\title{
Specificity of the Best Possible Self intervention for increasing optimism: Comparison with a gratitude intervention
}

\section{Especificidad de una intervención sobre el Mejor Self Posible para incrementar el optimismo: Comparación con una intervención de gratitud}

\author{
Madelon L. Peters \\ Yvo M. C. Meevissen \\ Marjolein M. Hanssen \\ Department of Clinical Psychological Science, Maastricht University, The Netherlands
}

(Rec: 28 de noviembre de 2012 / Acep: 09 de enero de 2013)

\begin{abstract}
The present study compared the effects of a one week best possible self intervention and a one week gratitude intervention on life satisfaction and optimism. We hypothesized that both interventions would lead to similar increases in life satisfaction, but that only the best possible self intervention would increase optimism. The results partly confirmed the hypotheses: only the best possible self intervention led to increased optimism immediately after the intervention period, which further increased one week after completion of the intervention. However, the best possible self intervention was also more effective in increasing life satisfaction than the gratitude intervention. Whereas the increase in life satisfaction in the best possible self intervention was significantly different from the control intervention, this was not the case in the gratitude condition. We conclude that the best possible self intervention is an effective exercise if one aims to increase optimism. Keywords: Best Possible Self intervention, Gratitude intervention, satisfaction with life, optimism, specificity
\end{abstract}

\section{Resumen}

El presente estudio comparó los efectos en satisfacción vital y optimismo de dos intervenciones (mejor self posible y gratitud), de una semana de duración. Hipotetizamos que ambas intervenciones incrementarían la satisfacción vital pero que la intervención del mejor self possible sería mejor para incrementar el optimismo. Los resultados confirmaron las hipótesis: sólo la intervención del mejor self posible condujo a un incremento en optimismo, que incluso se incrementó una semana después de la intervención. Sin embargo, la intervención del mejor self posible también fue más efectiva que la intervención en gratitud para incrementar la satisfacción vital. Mientras que el aumento en la satisfacción vital en la intervención del mejor self posible fue significativamente mayor que en el grupo de control, no sucedió lo mismo en la condición de gratitud. Concluimos que la intervención del mejor self posible es un ejercicio útil si se pretende incrementar el optimismo.

Faltan Palabras: intervención sobre el mejor self posible, intervención, gratitud, satisfacción con la vida, optimismo, especificidad. 


\section{Introduction}

With the advance of the positive psychology movement, various exercises and interventions have been developed to increase the wellbeing of people, either delivered as single exercises (Seligman, Steen, Park \& Peterson, 2005) or as a package (Schueller \& Parks, 2012; Seligman, Rashid \& Parks, 2006). A meta-analysis of the efficacy of positive interventions demonstrated the overall effectiveness of a variety of such interventions on wellbeing and depressive symptoms ( $\operatorname{Sin} \&$ Lyubomirsky, 2009). One of the simplest yet very effective exercises for increasing happiness is the so called "three good things exercise", also referred to as the counting-blessings exercise (Seligman et al., 2005; Mongrain \& AnselmoMatthews, 2012). This exercise teaches people to attend to positive things in their daily life by writing down three good things that happened that day and why these happened. Out of five different positive exercises (gratitude visit, three good things, you at your best, identifying signature strengths, using signature strengths) that were delivered through the internet the three good things exercise appeared to be one the most effective exercises in increasing happiness and decreasing depressive symptoms up to 6 months (Seligman et al, 2005).

Comparable to the three good things exercise are the so called gratitude exercises. In this exercise, participants make a list or keep a diary of things in their life they are grateful for.

Wood, Froh \& Geraghty (2010) reviewed the effectiveness of gratitude interventions and concluded that these are promising techniques that can be useful for clinical practice. Because of their ease of implementation and self-reinforcing properties they have potential for wide dissemination.

Another well researched positive psychology exercise is the "best possible self" (BPS) intervention. In contrast to the three-good-things/gratitude exercises, the BPS exercise is future oriented. People are instructed to write and think about their life in future where everything has turned out in the best possible way and they have realized all their life dreams. A few days of positive future thinking has shown to increase positive affect and psychological wellbeing (King, 2001; Sheldon \& Lyubomirsky, 2005). Because of its future focus the best possible self technique might also be specifically suitable for increasing optimism. The initial study introducing the BPS demonstrated that it had a significant effect on a composite measure consisting of satisfaction with life and dispositional optimism (King, 2001). We recently set out to specifically test whether the BPS intervention can be used as an optimism intervention (Peters, Flink, Boersma \& Linton, 2010). An imagery component was added to the exercise, because imagery has been found to exert stronger effects on emotions and cognition than verbal processing of the same material (Holmes, Lang, \& Shah, 2009). We found that a single session of BPS writing and imagery led to more positive expectancies about the future and that this effect was independent of the concomitant increase in positive affect (Peters et al., 2010). The effect of a single session BPS exercise on future expectancies was replicated in two subsequent experiments (Hanssen et al., 2013; Boselie et al., 2012). Moreover, we demonstrated that two weeks of daily BPS imagery led to a significant increase in dispositional optimism (Meevissen et al., 2011).

However, we do not know whether the BPS intervention is a specific intervention for increasing optimism or that other positive interventions could be equally effective in this respect. In fact, little is known on the differential effects of the various positive interventions. Recently Mongrain \& Anselmo-Matthews (2012) questioned the fact that positive psychology exercises have unique qualities or specific ingredients. It may be that they all have a more or less common mechanism, being positive thinking. Positive thinking, whether it is about the past, present or future, may fuel the upward spiral of positive emotions and positive resources as suggested by the broaden and build theory (Frederickson, 2001). If this is the case, other interventions that are able to increase positive emotions could be as effective as the BPS intervention in increasing optimism (and other positive resources).

In the present study we wanted to test the specificity of the BPS as an optimism intervention. We compared the effects of a BPS intervention, gratitude intervention and control intervention, each delivered for one week. We hypothesized that both the gratitude and the BPS interventions would lead to comparable increases in wellbeing compared to the control intervention, but that the BPS intervention would have a larger effect on optimism than the gratitude intervention. We also examined whether the effects on wellbeing and/or optimism persist after the intervention has ended, or whether there would even be a delayed effect on optimism, in accordance with the premises that the "building" component may need time. Therefore we assessed wellbeing and optimism immediately after completion of the intervention and one week later. 


\section{Methods}

\section{Participants}

Ninety participants were initially included in the study of which 82 (13 males, 69 females) provided 1-week follow up data and were used in the analyses. Mean age of these 82 participants was 22.8 years (range: $18-65 ; 95 \%<40$ years), all but one (had) followed university or advanced professional training. Participation was remunerated with a gift voucher or in partial fulfillment of credit points. The study was approved by the institute's Ethical Committee.

\section{Interventions}

In order to disguise the true purpose of the intervention and to avoid demand effects, participants were informed that they would practice imagery for one week in order to improve their spatial orientation abilities. A bogus spatial orientation test was administered pre- and post intervention to support credibility of the rational.

All three interventions had an identical format and consisted of a 1-hour individual introductory session at the research lab followed by one week of daily imagery exercises performed at home. During the lab session, a 5-minute training was provided in order to familiarize participants with imagery. Participants received instructions through headphones to imagine a lemon using all their senses, and to concentrate on the sensations and emotions attached to the images (cf. Holmes, Coughtrey, \& Connor, 2008). Next, participants received the specific instructions appropriate for their condition. All instructions were presented on screen and the computer signaled the timing of the different parts.

$B P S$ condition. Participants were asked to write about their best possible self in the future. In order to help them identify their core values we first asked them to think about how they wanted to be remembered at the end of their life by their loved ones. We provided them with three different domains to guide their imagery: a personal domain, a relational domain and a professional domain. Next they were given $3 \times 5$ minutes to write about their best possible self in each of the three domains. At the conclusion of the writing phase they had to extract the two most important qualities for each domain and formulate these as statements of future achievement (i.e.: In the future I will be...). Finally, they performed a 5-minute imagery exercise with one of the statements of their choice. They were instructed to repeat this imagery exercise once a day at home during the next week choosing a different statement each day.
Gratitude condition. Participants were instructed to focus on the positive aspects of their life and think about all the things they were grateful for. As in the BPS condition, they were asked to think about this in relation to three different domains (personal, relational and professional) and to write about each domain for 5 minutes. Next they identified the two most important things they were grateful for in each domain and formulated these into statements starting with "I am grateful for..". They chose one statement for their 5 -minute imagery exercise in the lab and were instructed to imagine a different statement each day during the next week.

Control condition. Participants were asked to focus their attention on the details of everyday occurrences and write down as many activities that frequently occur in a typical day in each of three domains, being spare time, social domain and professional domain. They wrote for 5 minutes for each domain and then structured their activities into the 6 most important ones (2 for each domain). As in the other two conditions they performed the 5-minute imagery exercise choosing one of the six activities and were instructed to imagine a different activity each day during the next week.

\section{Measures}

\section{Wellbeing}

Wellbeing was measured with the Satisfaction With Life Scale (SWLS; Diener, Emmons, Larsen \& Griffin, 1985). Participants score their level of agreement with each of 5 statement, using a 7 -point scale $(1=$ strongly disagree $-7=$ strongly agree). The total SWLS score is represented as the total score of the 5 items, higher scores indicating more satisfaction with life.

\section{Optimism}

The revised Life Orientation Test- (LOT-r; Scheier, Carver \& Bridges, 1994) was used to measure dispositional optimism. The LOT-r has six items (plus four filler items) that are rated on a 5 -point scale $(1=$ disagree $-5=$ agree $)$. Three items are positively phrased and three items are negatively phrased. A total optimism score can be obtained by summing all items after reversing the scores on the negatively phrased items.

In addition, we measured optimistic explanatory style with the Attributional Style Questionnaire (ASQ; Seligman, Abramson, Semmel, \& von Baeyer, 1979). The ASQ consists of 12 hypothetical events, 6 good (e.g. "You meet a friend who compliments you on your appearance") and 6 bad ("You have been looking for a job unsuccessfully for some time"). For each event, participants are asked to write down the one 
major cause of each event, imagining this event would occur to them. The hypothetical cause is then rated on a 7-point scale for three causal dimensions: 1 . internal versus external; 2. stable versus unstable; and 3. global versus specific. A total ASQ score is obtained by averaging the scores over all three dimensions per event, and calculating a grand average of scores on the positively stated items and the reverse scores on the negatively stated items. Higher scores on this scale represent a more optimistic attribution style.

\section{Manipulation checks}

During the one week of imagery exercises at home, participants filled out an imagery diary. This diary contained questions about the timing and content of the imagery, how easy it was to focus on the imagery and how motivated they were to perform the exercise. The latter questions were scored on a 9-point scale ( $1=$ very difficult $-9=$ very easy). Mean focus and mean motivation during the week was calculated.

\section{Procedure}

Participants were recruited by flyers that were posted across the university premises. After obtaining informed consent, they filled out the questionnaires through the internet on the day before their first lab visit. In addition to the above mentioned questionnaires, the package also contained several questions on spatial orientation for the purpose of providing a bogus rational for the study (i.e. improving spatial orientation by practicing imagery). During the initial lab session participants received the general imagery training followed by the writing and imagery exercises appropriate for their condition. At the end of the session participants had to solve a small 3-D puzzle task, again as a distracter for the true purpose of the study.

The instructions of the home imagery exercises were given in a manual that participants took home. In the BPS and gratitude conditions they had to imagine one of the statements in the personal domain on the first day, the relational domain on the next day and the professional domain on the third day. On the next three days they had to imagine the other statement of that domain in the same order. On the last day they could use a topic of their own choice. In the control condition the order was: spare time, social domain, professional domain.

Participants returned to the lab after exactly one week. First they filled out the same set of questionnaires, and this was followed by another imagery session. After the imagery exercise participants had to solve the same 3-D puzzle as in the first session to reinforce their belief that the research concerned spatial orientation. One week later, they received the last questionnaire package by e-mail which they had to complete and send back the same day. No instructions regarding the continuation of imagery exercises during this week were given. After returning the last set of questionnaires participants were debriefed.

\section{Statistical analyses}

First, it was checked whether there were any differences between the conditions in sex and age of the participants, or baseline scores of all the outcome measures. In addition, mean level of motivation and focus during the imagery exercises were compared between the conditions.

To test for differences in the effects of the interventions we first calculated change scores from baseline for the week-1 and week-2 assessments of SWLS, LOT-r and ASQ. The week-1 change score indicates the immediate intervention effect, the week- 2 change score represents a persisting or delayed effect. The two change scores were subjected to repeated measures ANOVA with time (i.e. week-1, week-2) as within-subjects factor and condition (i.e. control, BPS, gratitude) as between-subjects factor. The Greenhouse-Geisser correction was applied to the within-subjects effect in case of non-sphericity. Follow-up analyses with pairwise comparison of the three conditions on the week-1 and week- 2 change scores separately were performed when either the condition or condition $\mathrm{x}$ time effect was significant or showed a trend towards significance (i.e. $\mathrm{p}<.10$ ). Finally, a repeated measures ANOVA with the scores on all three assessment points was carried out within each condition separately to check whether a linear trend or a quadratic trend was present, indicating respectively an ongoing increase is the positive resources from baseline to the week-2 assessment or an initial increase followed by a decrease from week 1 to week 2 when the intervention had ended. All analyses were performed using SPSS 18.

\section{Results}

\section{Descriptive analyses}

Ninety participants were randomized to the three conditions. Eight participants did not return their 1-week follow-up questionnaire, resulting in a final number of 28 
participants in both the BPS and control condition and 26 participants in the gratitude condition.

Table 1 shows the means for the baseline and control variables per condition. There were no significant differences between the groups in sex, age, or satisfaction with life, dispositional optimism and optimistic attributions at baseline. Nor did the groups differ in mean motivation to perform imagery or mean focus during imagery. Most participants indicated to be moderately motivated and moderately focused. Analyses on scores of motivation and focus across the seven days indicated that the level of motivation/focus did not significantly change during the intervention week.

\section{Intervention effects}

Figures 1 to 3 show the scores on the SWLS, LOT-r and ASQ at each of the three time points in the three conditions. First, the two difference scores were subjected to repeated measures ANOVA. For SWLS the condition main effect showed a trend towards significance $(\mathrm{F}(2,79)=2.56$; $\mathrm{p}=.084)$ and therefore follow-up analyses were undertaken. Univariate analyses of variance on the week-1 and week2 change scores with pairwise comparison of conditions showed that the BPS condition significantly differed from the control condition on the week-1 assessment $(F(1,54)=$

Table 1. Sex distribution, baseline scores of outcome measures and motivation and focus during imagery in the three groups

\begin{tabular}{lccccc}
\hline & $\begin{array}{c}\text { BPS } \\
(\mathrm{n}=28)\end{array}$ & $\begin{array}{c}\text { Gratitude } \\
(\mathrm{n}=26)\end{array}$ & $\begin{array}{c}\text { Control } \\
(\mathrm{n}=28)\end{array}$ & $F$ & $p$ \\
\hline Sex $(\mathrm{M} / \mathrm{F})$ & $4 / 24$ & $5 / 21$ & $4 / 24$ & & \\
Age & 20.8 & 25.5 & 22.2 & 2.80 & .06 \\
& $(2.0)$ & $(11.9)$ & $(5.3)$ & & \\
SWLS & 24.71 & 25.73 & 26.04 & .61 & .55 \\
& $(5.18)$ & $(4.33)$ & $(4.51)$ & & \\
LOT-r & 15.93 & 16.50 & 16.25 & .23 & .80 \\
& $(3.20)$ & $(3.51)$ & $(2.65)$ & & \\
ASQ & 35.15 & 34.83 & 35.26 & .18 & .84 \\
& $(2.52)$ & $(3.24)$ & $(2.22)$ & & \\
Motivation & 5.46 & 5.41 & 5.31 & .06 & .94 \\
& $(1.37)$ & $(1.41)$ & $(1.59)$ & & \\
Focus & 5.74 & 5.31 & 5.49 & .48 & .62 \\
& $(1.44)$ & $(1.13)$ & $(1.68)$ & & \\
\hline
\end{tabular}

Note. Standard deviations appear in parentheses bellow means. SWLS: Satisfaction With Life Scale; LOT-r: Life Orientation Test -revised; ASQ: Attributional Style Questionnaire.
7.10; $\left.\mathrm{p}=.010, \eta^{2}=.116\right)$ and showed a trend towards a significant difference form the control condition for the week-2 assessment $\left(\mathrm{F}(1,54)=3.77 ; \mathrm{p}=.057, \eta^{2}=.065\right)$. The gratitude condition did not differ from the control condition on either time point, nor did the gratitude and BPS condition differ from each other. Nevertheless figure 1 suggests an ongoing increase in satisfaction with life in both active intervention conditions. This suggestion was confirmed by repeated measures ANOVA within conditions using the scores on each of the three time points. While the control condition did not show a significant linear or quadratic trend both the BPS and the gratitude condition did show a significant linear increase in SWLS scores across time points $(\mathrm{F}(1,27)=9.57, \mathrm{p}=.005$ for BPS and $\mathrm{F}(1,25)=5.37, \mathrm{p}=.029$ for gratitude) .

For dispositional optimism the condition effect was not significant but the time $\mathrm{x}$ condition effect showed a trend towards significance $(F(2,79)=2.85 ; \mathrm{p}=.064)$. Univariate testing with pairwise comparison of the week-1 and week-2 assessments showed that the conditions did not differ in the increase in optimism immediately after the intervention, but that at the one week follow-up assessment the increase in optimism was larger in the BPS condition than in both the control $\left(F(1,54)=3.79 ; \mathrm{p}=.057, \eta^{2}=.066\right)$ and the gratitude condition $\left(\mathrm{F}(1,52)=3.85 ; \mathrm{p}=.055, \eta^{2}=.065\right)$, although these effects just failed to reach significance. From figure 2 it appears that whereas optimism at first increased in all conditions, only in the BPS condition there was a further increase one week after the intervention had ended. This was corroborated by repeated measures ANOVA on the three time points within conditions which showed that only within the BPS condition the linear time trend reached significance $(F(1,27)=17.9 ; \mathrm{p}<.001)$.

Analyses of the change scores of the ASQ showed a significant condition effect $(\mathrm{F}(2,79)=3.28, \mathrm{p}=.043)$, without a time $\mathrm{x}$ condition interaction. Univariate analyses with pairwise comparisons indicated that at the week-1 assessment, only the BPS condition differed significantly from the control condition $\left(F(1,54)=5.38, p=.024, \eta^{2}=\right.$ .091). At the week-2 assessment again, the only difference was between the BPS and control condition $(\mathrm{F}(1,52)=4.32$, $\left.\mathrm{p}=.043, \eta^{2}=.080\right)$. No time trends were detected with repeated measures ANOVA in the control or gratitude condition, whereas in the BPS condition the linear time trend showed a trend towards significance $(F(1,27)=3.35$, $\mathrm{p}=.078)$, whereas the quadratic trend was significant $\mathrm{F}(1,27)=9.62, \mathrm{p}=.004$. This indicates an initial increase in optimistic attributions in the BPS condition, which lessens after the one week follow-up period. 


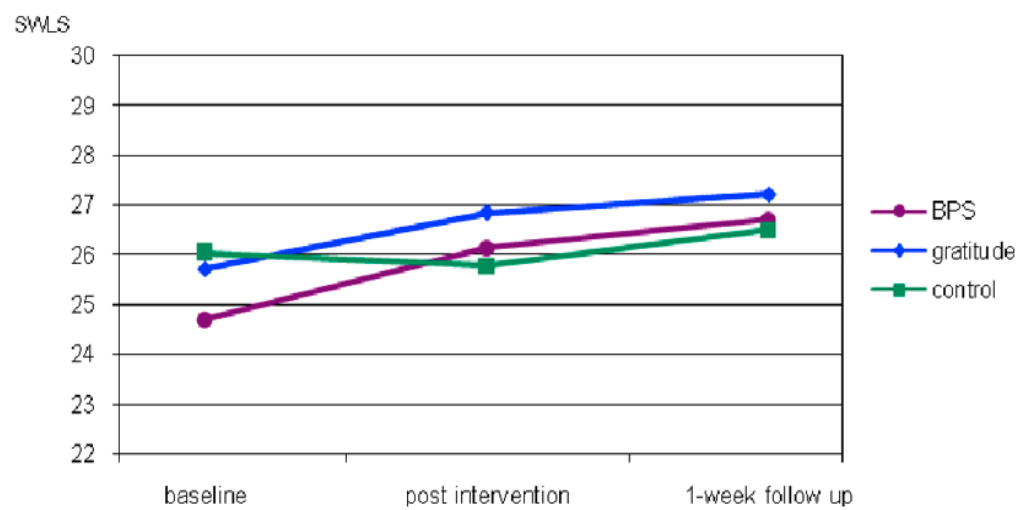

Figure 1. Wellbeing as measured by the SWLS at baseline, immediately post intervention and at one week follow-up per condition.

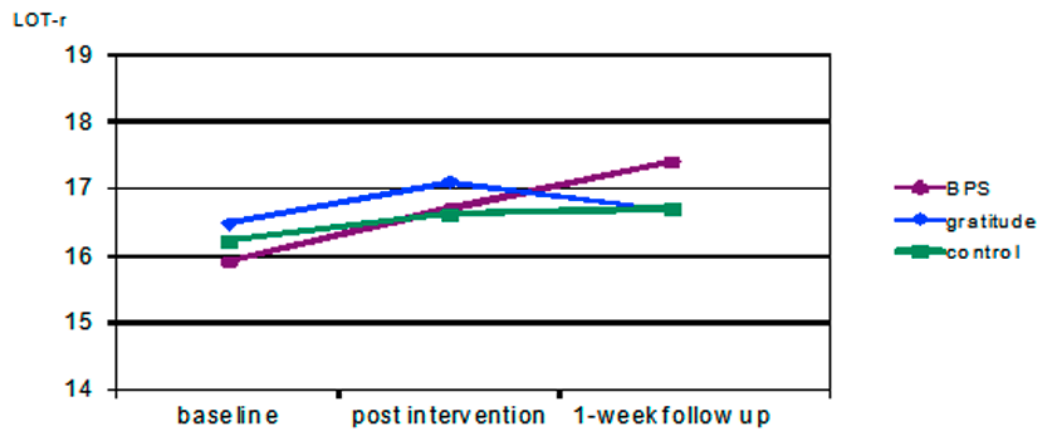

Figure 2. Dispositional optimism as measured by the LOT-r at baseline, immediately post intervention and at one week follow-up per condition.

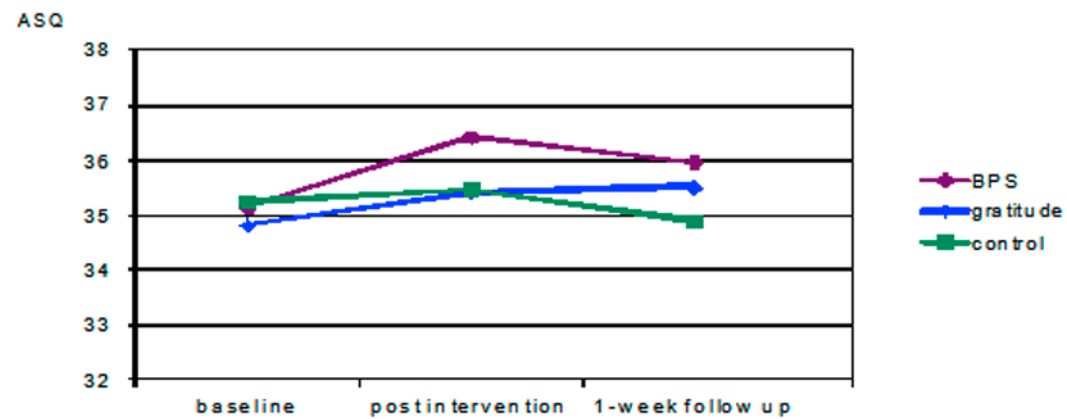

Figure 3. Optimistic attributions as measured by the ASQ at baseline, immediately post intervention and at one week follow-up per condition.

\section{Discussion}

The results of the study can be summarized as follows. One week of Best Possible Self imagery led to significant increases in both satisfaction with life and optimism. This increase was significantly larger than the increase in the control condition for satisfaction with life and optimistic attributions immediately after the intervention. The increase in satisfaction with life persisted at the one week follow-up assessment, while optimistic attributions diminished somewhat, even though it was still significantly higher at the week-2 assessment than at baseline. Dispositional optimism increased further after completion of the intervention and was almost significantly different from the control intervention 
at week-2. All effect sizes of the univariate comparisons between the BPS and control conditions were moderate.

The gratitude intervention seemed to be less effective. Whereas the time trend showed a significant increase in satisfaction with life from baseline to the week-1 and week-2 assessment, neither time point was significantly different from the control condition. Nevertheless there was also no difference from the BPS condition, suggesting that the effects fall in between the two conditions. Notably, there appeared to be no effect of the gratitude intervention on either dispositional optimism or optimistic attributions.

We hypothesized that the BPS and gratitude intervention would both be able to increase wellbeing, but that BPS would be more effective in increasing optimism. Our hypothesis was partly confirmed, with the gratitude condition not showing any effect on either dispositional optimism or optimistic attributions. However, the gratitude condition was also less effective in increasing wellbeing and thus it is difficult to draw a firm conclusion on the specificity of the BPS manipulation. It is possible that increasing wellbeing is a prerequisite for later increases in trait optimism. This would be consistent with the premises of the broaden and build theory that the broadening effect of positive emotions over time build personal resources (Frederickson, 2001). The building effect may thus take place only after the initial increase of positive emotions (e.g., Frederickson \& Joiner, 2002; Frederickson, Tugade, Waugh \& Larkin, 2003). Indeed, our results showed that dispositional optimism was only different from the control condition one week after the end of the BPS intervention. In the absence of a substantial effect on wellbeing, the (delayed) effect on optimism may also be lacking. Thus, whether the BPS intervention is actually superior in building optimism compared to other positive interventions remains to be determined.

The present study largely replicated our previous findings with a 2-week BPS intervention (Meevissen et al., 2011) where dispositional optimism also showed an ongoing increase from one to two weeks after the start of the intervention. However, the difference with the present study was that in the previous study the intervention was still ongoing in the second week. Given the present results, one week of BPS imagery might already suffice to lead to ongoing increases in optimism, although the persistence of the effect at longer follow-up times remains to be determined. Another difference is that the present study indicated a significant increase in wellbeing from baseline to two weeks after the start of BPS imagery, while in the previous study the increase in positive affect from baseline to one and two weeks was not significant (although there was a significant effect on positive affect when the BPS intervention was compared to the control intervention). Satisfaction of life may be a more stable measure of someone's subjective wellbeing than a single assessment of positive affect, which may be more influenced by daily events.

Previous studies have found gratitude interventions to increase positive affect, life satisfaction and decrease worrying and physical symptoms (Emmons \& McCullough, 2003; Froh et al., 2008; Geraghty et al., 2010; Watkins et al., 2003). In the present study using mostly young healthy volunteers the gratitude intervention was only marginally effective in increasing life satisfaction, which was not significantly different from increase in the control intervention. It should be noted that the content of the gratitude intervention used in the present study deviated from previous interventions. We tried to keep the format of all three interventions as similar as possible, controlling for potential non-specific effects of the exercises. Thus, all interventions involved writing about a topic relevant for the respective intervention, clustering the story into 6 statements relating to 3 different domains, followed by 1 week of imagery about one of these statements. Thus, also in the gratitude condition participants contemplated daily about one previous identified situation/ occurrence for which they were grateful. This may be less powerful than identifying new (and potentially more) situations/occurrences each day for which you can be grateful. Nevertheless, it may be noted that a previous study comparing gratitude and BPS also found gratitude to be less effective than BPS in increasing positive affect (Sheldon \& Lyubomirsky, 2006). Similar to the present study, BPS significantly increased positive affect whereas the effect of gratitude fell in between the control and the BPS condition and did not differ significantly from either.

It should be acknowledged that most of the effects in the present study were small, and often only showed a trend towards significance. One of the reasons could be that the control intervention also had some effect on the outcome measure in the study. This could either be due to demand or expectancy effect, or it might have had an active ingredient after all. Participants in the control condition also used daily imagery and they were instructed to attend to the details in their life. Although not instructed to specifically focus on positive events, participants may have been more inclined to select positive experiences as these are more motivating to imagine in a daily basis. It may also be that daily imagery in itself, irrespective of its content, has positive effects on wellbeing. The small positive effect in the control condition may have lessened the power to detect differences between the conditions, especially because sample size was relatively modest. Within conditions, analyses did 
indicate that the increase in life satisfaction was significant in both the BPS and gratitude condition.

Another reason for the marginally significant effects may be that participants were not seeking to become happier, and thus their motivation to engage in the daily exercises might have been low. Recently Lyubomirsky and colleagues (2011) demonstrated that it takes both will and effort to achieve durable changes in happiness When participants were recruited to the study under a false pretext, the happiness interventions were not effective whereas they were when participants self-selected for a happiness intervention (Lyubomirsky, Dickerhoof, Boehm \& Sheldon, 2011). In the present study participants were selected for a study on "imagery to increase spatial orientation". Thus, they were not specifically seeking to become happier. Nevertheless, motivation to perform the exercises was moderately high for most participants. The difference with the Lyubomirsky et al., (2011) study is that in this case, participants did opt for a study that promised them a potential benefit, namely increased spatial ability. This may have increased their motivation to actually engage in the exercises.

The purpose of the study was to examine the specificity of the BPS intervention to increase optimism compared to another positive psychology exercise, namely gratitude, in addition to a more generalized effect on wellbeing. We did find that one week of BPS imagery was more effective in increasing optimism than gratitude imagery, but the results should be viewed with caution because the gratitude exercise was generally less effective. Future studies should provide a more definitive answer by comparing the BPS intervention with a happiness intervention that is more powerful. Nevertheless, we confirmed once more that the BPS intervention is a suitable exercise if one aims to increase optimism.

\section{References}

Boselie, J., Peters, M. L., \& Vancleef, L. M. G. (2012). Bridging the gap: Does increasing optimism protect against the deteriorating effect of pain on executive task performance? (Unpublished master thesis, Maastricht University).

Diener, E., Emmons, R. A., Larsen, R. J., \& Griffin, S. (1985). The Satisfaction with life Scale. Journal of Personality Assessment, 49, 71-75

Emmons, R. A., \& McCullough, M. E. (2003). Counting blessings versus burdens: An experimental investigation of gratitude and subjective well-being in daily life. Journal of Personality and Social Psychology, $84,377-389$.

Fredrickson, B. L. (2001). The role of positive emotions in positive psychology - The broaden-and-build theory of positive emotions. American Psychologist, 56, 218-226

Fredrickson, B. L., \& Joiner, T. (2002). Positive emotions trigger upward spirals toward emotional well-being. Psychological Science, 13, $172-175$
Fredrickson, B. L., Tugade, M., Waugh, C. E., \& Larkin, G. R. (2003). What good are positive emotions in crises? A prospective study of resilience and emotions following the terrorist attacks on the United States on September 11th, 2001. Journal of Personality and Social Psychology, 84, 365-376.

Froh, J. J., Sefick, W. J., \& Emmons, R .A. (2008). Counting blessings in early adolescents: An experimental study of gratitude and subjective well-being. Journal of School Psychology, 46, 213-233

Geraghty, A. W. A., Wood, A. M., \& Hyland, M. E. (2010). Dissociating the facets of hope: Agency and pathways predict attrition from unguided self-help in opposite directions. Journal of Research in Personality, $44,155-158$

Hanssen, M. M., Peters, M. L., Vlaeyen, J. W. S., Meevissen, Y. M. C., \& Vancleef, M. G. (2013). Optimism lowers pain: Evidence of the causal status and underlying mechanisms. Pain, 154, 53-58

Holmes, E. A., Coughtrey, A. E., \& Connor, A. (2008). Looking at or through rose tinted glasses? Imagery perspective and positive mood. Emotion, 8, 875-879

Holmes, E. A, Lang, T. J., \& Shah, D. M. (2009). Developing interpretation bias modification as a 'cognitive vaccine' for depressed mood: Imagining positive events makes you feel better than thinking about them verbally. Journal of Abnormal Psychology, 118, 76-88

King, L. A. (2001). The health benefits of writing about life goals. Personality and Social Psychology Bulletin, 27, 798-807

Lyubomirsky, S., Dickerhoof, R., Boehm, J. K., \& Sheldon, K. M. (2011). Becoming happier takes both a will and a proper way: An experimental longitudinal intervention to boost well-being. Emotion, 11, 391-402

Meevissen, Y. M., Peters, M. L., \& Alberts, H. J. (2011). Become more optimistic by imagining a best possible self: effects of a two week intervention. Journal of Behavior Therapy and Experimental Psychiatry, $42,371-378$

Mongrain, M., \& Anselmo-Matthews, T. (2012). Do positive psychology exercises work? A replication of Seligman et al., (2005). Journal of Clinical Psychology, 68, 382-389.

Peters, M. L., Flink, I. K., Boersma, K., \& Linton, S. J.(2010). Manipulating optimism: can imagining a best possible self be used to increase positive future expectancies? Journal of Positive Psychology, 5, 204-211

Scheier, M. F., Carver, C. S., \& Bridges, M. W. (1994). Distinguishing optimism from neuroticism (and trait anxiety, self-mastery, and self-esteem): a reevaluation of the Life Orientation Test. Journal of Personality and Social Psychology, 67, 1063-1078

Schueller, S. M., \& Parks, A. C. (2012). Disseminating self-help: positive psychology exercises in an online trial. Journal of Medical Internet Research, 14(3): e63

Seligman, M. E. P., Abramson, L. Y., Semmel, A., \& von Baeyer, C. (1979). Depressive attributional style. Journal of Abnormal Psycho$\log y, 88,242-247$

Seligman, M.E.P., Rashid, T., \& Parks, A. C. (2006). Positive psychotherapy. American Psychologist, 61, 774-788

Seligman, M. E. P., Steen, T. A., Park, N., \& Peterson, C. (2005). Positive psychology progress: Empirical validation of interventions. American Psychologist, 60, 410-421

Sheldon, K. M., \& Lyubomirsky, S. (2006). How to increase and sustain positive emotion: The effects of expressing gratitude and visualizing best possible selves. Journal of Positive Psychology, 1, 73-82

Sin, N. L., \& Lyubomirsky, S. (2009). Enhancing well-being and alleviating depressive symptoms with positive psychology interventions: A practice-friendly metaanalysis. Journal of Clinical Psychology, 65, 467-48.

Watkins, P. C., Woodward, K., Stone, T., \& Kolts, R. L. (2003). Gratitude and happiness: Development of a measure of gratitude, and relationships with subjective wellbeing. Social Behavior and Personality, 31, 431-45

Wood, A. M., Froh, J. J., \& Geraghty, A. W. (2010). Gratitude and wellbeing: A review and theoretical intergration. Clinical Psychology Review, 30, 890-905 